\title{
Factors associated with the severity of motor impairment in children with cerebral palsy seen in Enugu, Nigeria
}

\author{
S O Iloeje, ${ }^{1}$ MB BCh, FWACP (Paed); C C Ogoke, ${ }^{2}$ MBBS, FWACP (Paed) \\ ${ }^{1}$ Department of Pediatrics, University of Nigeria Teaching Hospital, Ituku-Ozalla, Enugu, Nigeria \\ ${ }^{2}$ Department of Pediatrics, Federal Medical Center, Owerri, Imo State, Nigeria \\ Corresponding author: C C Ogoke (chrischikere@yahoo.com)
}

\begin{abstract}
Background. Cerebral palsy (CP) is a heterogeneous condition that is well known to cause impairments with varying degrees of severity. The gross motor function classification system (GMFCS) is widely used to assess ambulatory function in CP, but little is known about the factors that account for the variations in gross motor function in children. The purpose of this study was to assess the relation between the severity of gross motor dysfunction (GMD) and certain factors such as the type of CP, aetiology of CP, nutrition, socioeconomic class (SEC), and the frequency of these accompanying impairments like visual, auditory, cognitive and speech impairments.

Methods. This was a cross-sectional observational study of 100 consecutively recruited CP patients aged 9 - 96 months, who attended the paediatric neurology clinics (PNCs) in Enugu between April and October 2010. Each patient's clinical history was recorded, a neurological examination conducted and GMFCS level ascertained. Statistical analyses were done to determine the association between the categorical variables.

Results. The type of CP $(p=0.000)$, aetiological factors $(p=0.016)$, the presence of malnutrition $(p=0.004)$ and the frequency of accompanying impairments ( $p=0.001$ ) were significantly associated with the severity of GMD, while SEC ( $p=0.649)$ had no significant association.

Conclusion. The type of $\mathrm{CP}$, aetiological factors, the presence of malnutrition and the number of accompanying physical, mental or physiological impairments, were positively associated with the severity of GMD and walking ability in children with CP.
\end{abstract}

S Afr J Child Health 2017;11(3):112-116. DOI:10.7196/SAJCH.2017.v11i3.1246

Cerebral palsy $(\mathrm{CP})$ is a neurodevelopmental disability. It is the most common cause of physical disability in childhood and occurs worldwide with a prevalence of $2-2.5$ per 1000 live births in the Western world. ${ }^{[1]}$ The prevalence of CP in Nigeria is unknown and the rate of children attending neurology clinics in Nigeria varies broadly from $16 \%$ to $50.3 \%{ }^{[2-4]}$ The University of Nigeria Teaching Hospital (UNTH), Enugu, reported $\mathrm{CP}$ to be the second most frequent neurological disorder seen in the paediatric neurology clinic (PNC); ${ }^{[2]}$ however, there is a paucity of studies on gross motor dysfunction (GMD) in CP in Africa.

The most current definition of $\mathrm{CP}$ is, ' $\mathrm{CP}$ describes a group of permanent disorders of the development of movement and posture causing activity limitation that are attributed to non-progressive disturbances that occurred in the developing fetal or infant brain. The motor disorders of cerebral palsy are often accompanied by disturbances of sensation, perception, cognition, communication and behaviour, by epilepsy and secondary musculoskeletal problems. ${ }^{[5]}$ These impairments are experienced to varying degrees and the severity of $\mathrm{CP}$ is based on a functional classification of these impairments. ${ }^{[1,5,6]}$ There are various functional scales, with the most popular one being the Gross Motor Function Classification System (GMFCS). GMFCS quantifies a child's gross motor function (ambulatory function) into five levels of severity, ranging from walking without restrictions (level I), to total dependence for ambulation (level V). ${ }^{[5,6]}$

Vasconcellos et al. ${ }^{[7]}$ in Brazil reported $34.3 \%$ of the study population as ambulatory while Nordmark et al ${ }^{[8]}$ in southern Sweden reported a much higher proportion of ambulatory patients (73\%). Medical research hasn't been able to explain this huge discrepancy. The aim of this study was to identify the factors that are associated with the severity of motor function, as determined by the GMFCS in children with CP in Enugu, Nigeria.

\section{Methods}

\section{Study sites}

The study was carried out in the PNCs of the UNTH, Ituku-Ozalla, and Enugu State University Teaching Hospital (ESUTH). The UNTH is one of the first-generation teaching hospitals in Nigeria. It has multidisciplinary departments and caters for patients from predominantly the south-eastern region of the country. The PNC of UNTH operates once a week and caters primarily for children who have neurological conditions and have been referred. ESUTH is a smaller and relatively new teaching hospital. Its PNC also runs once a week (on a different weekday).

\section{Sampling method}

This was a cross-sectional observational study. Sample selection was non-randomised and the subjects were consecutively recruited until the desired sample size was reached. Patients aged between 9 and 96 months with a diagnosis of $\mathrm{CP}$ were recruited. Patients with other movement disorders, physical disabilities and motor abnormalities, such as muscular dystrophies, paralytic poliomyelitis and spina bifida (myelomeningocele) were excluded.

\section{Ethical approval and consent}

This research was approved by the UNTH Research Ethics Committee and this was accepted by the ESUTH. Informed consent was obtained from the parents/guardians of the patients before recruitment and confidentiality of the patients' information was ensured.

\section{Study population}

The cohort consisted of $\mathrm{CP}$ patients, with a median age of 32 months (range 9 - 36), who attended the PNCs of the abovementioned teaching hospitals between April and October 2010. This age bracket was chosen in view of the age distribution found in a previous study of CP patients in Enugu. ${ }^{[9]}$ It is necessary to mention that spastic quadriplegics classified in this study as ambulatory included children walking with hand-held mobility devices and those who could propel a manual wheelchair (level III), and therefore should not be misconstrued only as those walking unaided. 


\section{Study protocol}

For each child, sociodemographic data, including parental level of education and occupation were ascertained and data were recorded. Relevant history about the antenatal, perinatal and postnatal periods and developmental milestones was recorded. The gross motor developmental milestones indicated a delay in acquisition of motor milestones in all cases without a regression or loss of milestones already achieved. History also indicated motor impairment and other CP-related symptoms such as epilepsy, visual, speech, cognitive and hearing impairments in the first 2 - 3 years of life. A consistent history and descriptions of motor findings, consistent with the most recent definition of $\mathrm{CP}$, were used to determine case status. ${ }^{[5]}$

Anthropometry was done to determine the nutritional state of each child. A flexible inelastic tape measure was used to measure the occipitofrontal circumference $(\mathrm{OFC})$ to the nearest $0.1 \mathrm{~cm}$. An infantometer was used to measure the length of children $<3$ years old and children who could not stand. The length of older, non-ambulatory patients (GMFCS level IV and $\mathrm{V}$ ) was measured using a flexible, inelastic tape measure. An assistant helped to hold their legs straight by pressing on the child's chest and knees to enable measurement from the top of the head to the soles. None of the patients had severe lower-limb contractures that required length measurement in segments. Children who could stand flat-footed and bear their own weights had their weights and heights measured with a standing scale equipped with a stadiometer (SM-160, Surgifield Medical, England). The basinet scale (Model 180, Salter, Australia) was used to weigh patients $\leq 15 \mathrm{~kg}$. None of the patients had a feeding gastrostomy.

Detailed age-adjusted neurological examinations were conducted and showed abnormalities of movement, posture, tone and reflexes (deep tendon and primitive). The number of impairments in each child was recorded and included speech, auditory and visual impairments, undernutrition, epilepsy, microcephaly, drooling and contracture.

The current motor abilities of each child in the home setting were ascertained from the parent/guardian. Subsequently, for each child the following motor abilities were assessed: head control and observed lying, sitting, crawling, standing, walking, running a few meters and climbing stairs. Each child's present ability and limitations were determined. Children who were $<18$ months old were assessed for head control, floorsitting with or without hand support, and whether the child could crawl or pull to stand. Using the GMFCS, each child was classified into one of five levels of severity by cross-checking the findings in the appropriate age band of the child. ${ }^{[10]}$ All findings were carefully recorded in the proforma.

\section{Data analysis}

Data were analysed using the statistical package for the social sciences (SPSS version 15; IBM Corp., USA.) The categorical variables (GMFCS) levels, type of $\mathrm{CP}$, socioeconomic class (SEC), aetiological factors, presence or absence of malnutrition, frequency of accompanying impairments) were further examined for association with GMD severity using Fisher's exact test; $(p<0.05)$. The SEC was obtained by calculating the mean value (to the nearest whole number) of the scores for the occupation and level of education of their parents or substitutes as recommended by Oyedeji. ${ }^{[11]}$ Based this information, the subjects were classified into upper class (I and II), middle class (III) and lower class (IV and V). The upper class correlated with high-income earners with formal education and adequate health knowledge, while the lower SEC represented lowincome earners who lacked formal education and social amenities. The middle classes were intermediate between high- and low-income earners.

The OFC of each child was plotted on the World Health Organization (WHO) head circumference-for-age child growth chart and those below the third percentile for their age were noted to have microcephaly ${ }^{[12]}$ The following anthropometric indices of the WHO child growth standards were used for analysis: weight-for-height $\mathrm{Z}$ scores (WHZ) and height-for-age $\mathrm{Z}$ scores (HAZ) ${ }^{[12,13]}$ Wasting and stunting were reported following the internationally recognised definitions proposed by WHO/UNICEF. Wasting (acute malnutrition) was defined as WHZ $<-2$ and severe wasting as $\mathrm{WHZ}<-3$. Stunting (chronic malnutrition) was defined as HAZ $<-2$ and severe stunting as HAZ $<-3$. $^{[12,13]}$ The distribution and types of malnutrition in our cohort is shown in Fig. 1.

\section{Results}

\section{Biodemographic characteristics of study population}

Out of the 100 consecutively recruited patients, there were 58 males and 42 females, giving a male:female gender ratio of 1.4:1. The mean (SD) age of the children was 32.0 (22.7) months. The mean (SD) age of males and females was 27.95 (18.3) and 37.69 (26.9) months, respectively. The patients comprised 43\% high SEC (I and II), 25\% middle SEC and 32\% low SEC individuals (Table 1).

\section{Association between severity of GMD and categorical variables \\ SEC and severity of GMD}

The severity of GMD in terms of ambulatory and non-ambulatory status was analysed in the context of the SEC of the study subjects. Differences in the distribution were not statistically significant $(p=0.649)$ (Table 1).

\section{Type of CP and severity of GMD}

The severity of GMD in relation to the type of CP was statistically significant, indicating an association between the type of $\mathrm{CP}$ and the severity of GMD ( $p=0.000)$ (Table 2). Spastic quadriplegia showed the highest correlation with severe GMD. Hemiplegic and hypotonic CP were associated with the lowest GMD.

\section{Aetiological factors and severity of GMD}

There was no significant association between the occurrence of single, multiple or unknown aetiological factors and the severity of GMD, ( $p=0.791$ ) (Table 3). However, different aetiological factors analysed in isolation showed a statistically significant correlation between the type of factor and the severity of GMD ( $p=0.0159)$. Children with postnatal central nervous system (CNS) infection as a single aetiological factor all had severe GMD, indicating the highest correlation with severe GMD (Table 4)

\section{Malnutrition and severity of GMD}

A greater proportion (65.1\%) of patients with normal nutritional status were ambulatory, while a greater proportion $(64.9 \%)$ with malnutrition were non-ambulatory. GMD and the presence of malnutrition showed a statistically significant association $(p=0.004)$ (Table 5$)$.

\section{Frequency of accompanying impairments and severity of GMD} The frequency of associated impairments was proportionate to the severity of the GMD. All patients with five or six associated impairments had severe GMD showing a statistically significant association $(p=0.001)$ (Table 6).

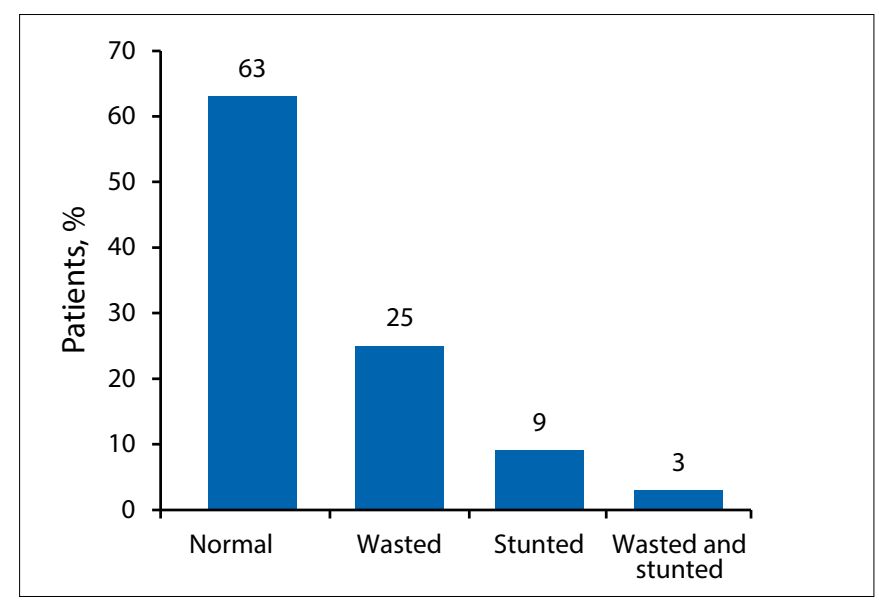

Fig. 1. Distribution and types of malnutrition in the patients. 
Table 1. Severity of GMD by SEC of patients $(N=100)$

\begin{tabular}{llll}
\hline & \multicolumn{2}{c}{ GMFCS severity } & \\
\cline { 2 - 3 } $\begin{array}{l}\text { Socioeconomic } \\
\text { class }\end{array}$ & $\begin{array}{l}\text { Ambulatory } \\
(\boldsymbol{n = 5 4 )}, \boldsymbol{n}(\%)\end{array}$ & $\begin{array}{l}\text { Non- } \\
\text { ambulatory } \\
(\boldsymbol{n}=\mathbf{4 6}), \boldsymbol{n}(\%)\end{array}$ & Total \\
\hline SEC I & $8(50.0)$ & $8(50.0)$ & 16 \\
SEC II & $15(59.3)$ & $12(40.7)$ & 27 \\
SEC III & $12(48.0)$ & $13(52.0)$ & 25 \\
SEC IV & $16(53.3)$ & $14(46.7)$ & 30 \\
SEC V & $2(100)$ & 0 & 2 \\
$\begin{array}{l}\text { GMD }=\text { gross motor dysfunction; SEC }=\text { socioeconomic class; GMFCS }=\text { gross } \\
\text { motor function classification system. } \\
\chi^{2}=2.475, d f=4, p=0.649 .\end{array}$ &
\end{tabular}

\section{Table 2. Severity of GMD by type of CP $(N=100)$}

\begin{tabular}{|c|c|c|c|}
\hline \multirow[b]{2}{*}{ Type of CP } & \multicolumn{2}{|c|}{ GMFCS Severity } & \multirow[b]{2}{*}{ Total } \\
\hline & $\begin{array}{l}\text { Ambulatory } \\
(n=54), \\
n(\%)\end{array}$ & $\begin{array}{l}\text { Non- } \\
\text { ambulatory } \\
(n=46), \\
n(\%)\end{array}$ & \\
\hline Spastic quadriplegia & $10(23.8)$ & $32(76.2)$ & 42 \\
\hline Spastic hemiplegia & $17(100)$ & 0 & 17 \\
\hline Spastic diplegia & $3(60.0)$ & $2(40.0)$ & 5 \\
\hline Extrapyramidal & $10(50.0)$ & $10(50.0)$ & 20 \\
\hline Hypotonic & $7(100)$ & 0 & 7 \\
\hline Mixed & $7(77.8)$ & $2(22.2)$ & 9 \\
\hline
\end{tabular}

Table 3. Aetiological factors and severity of GMD $(N=100)$

\begin{tabular}{llll}
\hline & \multicolumn{2}{c}{ Severity of GMD } & \\
\cline { 2 - 3 } & $\begin{array}{l}\text { Ambulatory } \\
(\boldsymbol{n = 5 4 )} \\
\boldsymbol{n ( \% )}\end{array}$ & $\begin{array}{l}\text { Non- } \\
\text { ambulatory, } \\
(\boldsymbol{n = 4 6 )} \\
\boldsymbol{n ( \% )}\end{array}$ & Total \\
\hline $\begin{array}{l}\text { Single aetiological } \\
\text { factor }\end{array}$ & $31(57.4)$ & $27(58.7)$ & 58 \\
$\begin{array}{l}\text { Multiple aetiological } \\
\text { factors }\end{array}$ & $21(38.9)$ & $16(34.8)$ & 37 \\
$\begin{array}{l}\text { Unknown } \\
\begin{array}{l}\text { GMD }=\text { gross motor dysfunction. } \\
\text { Fisher's exact test } p=0.791 .\end{array}\end{array}$ & $3(6.5)$ & 5 \\
\end{tabular}

\section{Discussion}

This study has shown that the factors associated with the severity of GMDs in $\mathrm{CP}$ patients are the neurological subtypes of $\mathrm{CP}$, the aetiological factors, malnutrition, and the number of accompanying impairments. Further studies may show the impact of reducing these factors on ambulatory function in CP patients. Spastic quadriplegia, postnatal CNS infections, malnutrition and highly prevalent accompanying impairments were most notably associated with more severe GMD in our patients. These findings are all consistent with previously published data on $\mathrm{CP} .^{[7,8,14,15]}$ However, this study showed no correlation between SEC status and the severity of GMD, irrespective of the fact that severely affected children survive longer if given superior support compared with those from low SEC environments who usually seek unorthodox interventions, or none at all.

\begin{tabular}{|c|c|c|c|}
\hline \multirow[b]{2}{*}{$\begin{array}{l}\text { Type of } \\
\text { aetiological factor }\end{array}$} & \multicolumn{2}{|c|}{ Severity of GMD } & \multirow[b]{2}{*}{ Total } \\
\hline & $\begin{array}{l}\text { Ambulatory } \\
(n=23), \\
n(\%)\end{array}$ & $\begin{array}{l}\text { Non- } \\
\text { ambulatory } \\
(n=46), \\
n(\%)\end{array}$ & \\
\hline Severe birth asphyxia & $13(61.9)$ & $8(38)$ & 21 \\
\hline Prematurity & $2(50)$ & $2(50)$ & 4 \\
\hline Kernicterus & $7(38.9)$ & $1161.1)$ & 18 \\
\hline $\begin{array}{l}\text { Postnatal CNS } \\
\text { infection }\end{array}$ & 0 & $5(100)$ & 5 \\
\hline $\begin{array}{l}\text { Infantile status } \\
\text { epilepticus }\end{array}$ & $1(10)$ & $9(90)$ & 10 \\
\hline
\end{tabular}

Table 5. Severity of GMD and malnutrition $(N=100)$

\begin{tabular}{|c|c|c|c|}
\hline \multirow[b]{2}{*}{ Malnutrition } & \multicolumn{2}{|c|}{ GMFCS severity } & \multirow[b]{2}{*}{ Total } \\
\hline & $\begin{array}{l}\text { Ambulatory } \\
(n=54) \\
n(\%)\end{array}$ & $\begin{array}{l}\text { Non- } \\
\text { ambulatory } \\
(n=46) \\
n(\%)\end{array}$ & \\
\hline Absent & $41(65.1)$ & $22(34.9)$ & 63 \\
\hline Present & $13(35.1)$ & $24(64.9)$ & 37 \\
\hline \multicolumn{4}{|c|}{$\begin{array}{l}\text { GMD }=\text { gross motor dysfunction; GMFCS }=\text { gross motor function classification } \\
\text { system. } \\
\chi^{2}=8.414, \mathrm{df}=1, p=0.004 .\end{array}$} \\
\hline
\end{tabular}

Table 6. Severity of GMD by frequency of accompanying impairments $(N=100)$

\begin{tabular}{lll}
\hline & \multicolumn{2}{c}{ GMFCS severity } \\
\cline { 2 - 3 } $\begin{array}{l}\text { Number of other } \\
\text { impairments }\end{array}$ & $\begin{array}{l}\text { Ambulatory } \\
(\boldsymbol{n = 5 4 )}, \boldsymbol{n}(\%)\end{array}$ & $\begin{array}{l}\text { Non- } \\
\text { ambulatory } \\
(\boldsymbol{n}=\mathbf{4 6}), \boldsymbol{n}(\%)\end{array}$ \\
\hline One & $19(82.6)$ & $4(17.4)$ \\
Two & $18(69.2)$ & $8(30.8)$ \\
Three & $10(38.5)$ & $16(61.5)$ \\
Four & $7(36.8)$ & $12(63.2)$ \\
Five & $0(0.0)$ & $5(100)$ \\
Six & $0(0.0)$ & $1(100)$
\end{tabular}

GMD = gross motor dysfunction; GMFCS = gross motor function classification system.

Fisher's exact test $p=0.01$.

This is surprising because patients from high SEC environments typically have normal nutritional statuses, they can commence early rehabilitation such as physiotherapy, and they have access to multidisciplinary hospital treatments - factors expected to positively affect gross motor abilities. The reason for the negative association is unclear and may require further investigation.

It is not surprising that spastic quadriplegia caused severe GMD; whole-body involvement usually results from extensive brain damage such as a diffuse CNS infection and severe birth asphyxia, resulting in severe hypoxic-ischaemic encephalopathy. Vasconscellos et al. ${ }^{[7]}$ and Nordmark et al.$^{[8]}$ reported spastic quadriplegic $\mathrm{CP}$ as predominantly nonambulatory, which is consistent with findings in this study. Interestingly, 
$24 \%$ of the spastic quadriplegics were ambulatory. Those children with spastic quadriplegia (severe and equal spasticity of all four limbs) differed clinically from the spastic diplegics (more severe lower- limb involvement) and had different aetiological factors (mostly severe birth asphyxia and postnatal CNS infections for spastic quadriplegics v. premature birth for spastic diplegics). However, this clinical assessment is subjective and the need to improve the reliability of $\mathrm{CP}$ classifications has given birth to the classification by surveillance for CP in Europe (SCPE) ${ }^{[16]}$ It is necessary to mention that spastic quadriplegics classified in this study as ambulatory included children walking with hand-held mobility devices and those who could propel a manual wheelchair (level III), and therefore should not be misconstrued only as those walking unaided. Furthermore, a greater proportion of the population studied (52\%) were $<24$ months old and some of the spastic quadriplegics (most prevalent type) could have been classified to better functioning levels because the GMFCS is less precise in infants $<24$ months old. ${ }^{[17]}$ This study, by classifying all children with hypotonic $\mathrm{CP}(7 \%)$ as ambulatory, differs significantly from the study by Pfeifer et al., ${ }^{[14]}$ who reported all children with hypotonic CP (3\%) as nonambulatory. The reason for this finding is unclear.

Due to a larger cortical representation of the hand and arm than the leg, upper-limb function is more impaired than lower-limb function and explains why patients with hemiplegia usually ambulate. All hemiplegic patients in this study were ambulatory and in agreement with the report by Gorter et al., ${ }^{[15]}$ who observed that the majority (87.8\%) of hemiplegic CP was classified as level I (mild GMD). Similar reports were made by Vasconcellos et al. ${ }^{[7]}$ and Nordmark et al. ${ }^{[8]}$ The findings of this study are consistent with previous studies, reinforcing that children with hemiplegic $\mathrm{CP}$ are not likely to require mobility aids, while those patients with spastic quadriplegia are more likely to need augmentative interventions. ${ }^{[7,8,14,15]}$

Though a small number (5\%) of our patients had postnatal CNS infections (bacterial meningitis) as a single aetiological factor, it is interesting to note that all of them had severe GMD. This occurred because the infections cause widespread brain damage resulting in spastic quadriplegia, which is frequently associated with severe GMD and an inability to ambulate independently.

The most recent definition of $\mathrm{CP}$ highlights the importance of accompanying physiological impairments and comorbidities in CP, by incorporating their occurrence as part of the definition of $\mathrm{CP}^{[5]}$ We found that all of our patients had at least one accompanying impairment. We sought to ascertain whether there was an association between the number of impairments and the severity of GMD, and not the effect of individual disorders such as epilepsy, on GMD. We hypothesised that a child with $\mathrm{CP}$ with a greater number of other impairments would have more severe GMD. As hypothesised, GMD became more severe with an increasing number of accompanying disorders $(p=0.001)$, suggesting that the total number of associated deficits in any child with CP may give an indication of the functional abilities of that child. This finding is supported by Vasconcellos et al. ${ }^{[7]}$ who observed that associated impairments were mainly evidenced at GMFCS levels IV/V. This finding suggests more severe damage to the developing motor areas of the brain with an increasing number of other impairments. Conversely, it is possible that the presence of severe GMD in a child with $\mathrm{CP}$ could be predisposed to a higher number of accompanying impairments. For instance, a child with spastic quadriplegia on GMFCS level $\mathrm{V}$ is at a greater risk of having hip subluxation/dislocation, contractures and, if adequately fed, develops obesity (malnutrition) because of immobilisation. In addition, oromotor dysfunction, sucking and swallowing difficulties in this child may result in undernutrition and increased risk of aspiration and pneumonia. However, another child with spastic quadriplegia who is on level I (mild GMD) faces less risk of these impairments by being independently mobile and having less severe motor dysfunction.

An earlier study in Enugu found that malnutrition was more prevalent (36\%) in children with CP than their controls. ${ }^{[18]}$ This prevalence rate was similar to our finding. Severe malnutrition negatively affects functional motor skills by impairing brain maturation, reducing motor activity and causing muscle weakness. Due to the relatively high prevalence of malnutrition in children with $\mathrm{CP}$ and its worsening effect on existing GMD, paediatricians should pay attention to the nutrition of newly diagnosed children. It should be noted that severe GMP, as seen in spastic quadriplegia, could manifest with oromotor dysfunction (due to pseudobulbar palsy) causing sucking and swallowing difficulties, which results in undernutrition. In this study, it does seem likely that poor nutrition was secondary to motor dysfunction, since most of the malnourished patients were non-ambulatory with severe GMD. This emphasises the need for alternative feeding modalities like gastrostomies, which are largely unavailable in Nigeria. Nasogastric tube feeding is an easier alternative feeding intervention and should be encouraged in those children with swallowing difficulties. The statistically significant association between the severity of GMD and malnutrition $(p=0.004)$ in this study is a valid finding, but with the realisation that this association could be bidirectional. Longitudinal or controlled studies are needed to learn more about this association.

\section{Limitations}

Some neurometabolic/neurodegenerative disorders present with motor dysfunction. None of the patients in this study had serum amino acids, organic acids, lactate, ammonia or urinary glycosaminoglycans measured (metabolic screen). It must therefore be acknowledged that the profile of aetiological factors presented in this study could have been influenced by both the investigative facilities available, e.g. no genetic/chromosomal studies or magnetic resonance imaging, as well as recall bias owing to the cross-sectional design of this study.

\section{Conclusion}

The type of $\mathrm{CP}$, aetiological factors, malnutrition and the number of accompanying impairments correlated statistically significantly with the severity of GMD. SEC did not correlate with GMD severity as expected and further clinical research is required to elucidate the reasons for this finding. Ultimately, there is a need for further research on the factors causing variations in GMD in different populations of children with CP.

Acknowledgements. We are grateful to our patients and their parents for participating in this study. We thank the staff of the Paediatric Neurology Clinics (PNCs) of UNTH and ESUTH, Enugu for their support.

Author contributions. SOI was involved in the conception and design of the topic; he revised the article critically for important intellectual content and gave the final approval of the version to be published. CCO made substantial contribution to the conception and design of the topic; he was involved in the acquisition of data, data analysis, interpretation and drafting of the article. Both authors read and agreed to the final manuscript.

Funding. None.

Conflicts of interest. None.

1. Rosenbaum P. Cerebral palsy: What parents and doctors want to know. Br Med J 2003;326(7396):970-974. https://doi.org/10.1136/bmj.326.7396.970

2. Izuora GI, Iloeje SO. A review of neurological disorders seen at the Paediatric Neurology Clinic of the University of Nigeria Teaching Hospital Enugu. Ann Trop Paediatr 1989;9(4):185-189. https://doi.org/10.1080/02724936.1989.11748629

3. Frank-Briggs AI, Alikor EAD. Pattern of paediatric neurological disorders in Port Harcourt, Nigeria. Int J Biomed Sci 2011;7(2):145-149.

4. Ogunlesi T, Ogundeyi M, Ogunfowora O, Olowu A. Socio-clinical issues in cerebral palsy in Sagamu, Nigeria. S Afr J Child Health 2008;2(3):120-124.

5. Bax M, Goldstein M, Rosenbaum P, Paneth N. Proposed definition and classification of cerebral palsy. Dev Med Child Neurol 2005;47:571-576. https:// doi.org/10.1017/s001216220500112x

6. Palisano R, Rosenbaum P, Walter S, Russell D, Wood E, Gluppi B. Development and reliability of a system to classify gross motor function in children with cerebral palsy. Dev Med Child Neurol 1997;39(4):214-223. http://dx.doi. org/10.1111/j.1469-8749.1997.tb07414.x

7. Vasconcellos RLM, Moura TL, Campos TF, Lindquist ARR, Guerra RO. Functional performance assessment of children with cerebral palsy according to motor impairment levels. Rev Bras Fisioter 2009;13(5):390-397. https:// doi.org/10.1590/s1413-35552009005000051 
8. Nordmark E, Hägglund G, Lagergren J. Cerebral palsy in southern Sweden 1II Gross motor function and disabilities. Acta Paediatr 2001;90(11):12771282. https://doi.org/10.1111/j.1651-2227.2001.tb01575.x

9. Iloeje SO, Ejike-Orji I. Compliance by cerebral palsy patients attending a child neurology service in a developing country. A preliminary study. W Afr J Med 1993;12(1):1-5

10. Palisano RJ, Rosenbaum P, Bartlett D, Livingston MH. Content validity of the expanded and revised Gross Motor Function Classification System. Dev Med Child Neurol 2008;50(10):744-750. 18834387. http://dx.doi.org/10.1111/ j.1469-8749.2008.03089.x

11. Oyedeji GA. Socioeconomic and cultural background of hospitalised children in Ilesa. Nig J Paediatr 1985;12(4):111-117.

12. WHO/UNICEF. WHO child growth standards and the identification of severe acute malnutrition in infants and children. A joint statement by the WHO \& UNICEF Geneva: WHO, 2009. http://www.who.int/nutrition/publications/ severemalnutrition/9789241598163/en/ (accessed 10 May 2015).

13. UNICEF. Tracking progress on child and maternal nutrition; a survival and development priority. Geneva: WHO, 2009. https://www.unicef.org/
publications/files/Tracking_Progress_on_Child_and_Maternal_Nutrition_ EN_110309.pdf (accessed 10 May 2015).

14. Pfeifer LL, Silva DBR, Funayama CAR, Santos JL. Classification of cerebral palsy: Association between gender, age, motor type, topography and gross motor function. Arq Neuropsiquiatr 2009;67(4):1057-1061. https://doi. org/10.1590/s0004-282x2009000600018

15. Gorter JW, Rosenbaum PL, Hanna SE, et al. Limb distribution, motor impairment and functional classification of cerebral palsy. Dev Med Child Neurol 2004;46(7):461-467. https://doi.org/10.1017/s0012162204000763

16. Surveillance of cerebral palsy in Europe. SCPE Collaborative Group: A collaboration of cerebral palsy surveys and registers. Dev Med Child Neurol 2000;42(12):816-824. https://doi.org/10.1017/s0012162200001511

17. Gorter JW, Ketelaar M, Rosenbaum P, Helders PJM, Palisano R. Use of the GMFCS in infants with CP: The need for reclassification at 2 years or older. Dev Med Child Neurol 2008;51(1):46-52. https://doi.org/10.1111/j.14698749.2008.03117.x

18. Okeke IB, Ojinnaka NC. Nutritional status of children with cerebral palsy in Enugu, Nigeria. Euro J Sci Res 2010;39(4):505-513. 